\title{
False positive results in right coronary artery areas of myocardial perfusion spect in patients with left bundle block and left ventricular dilatation
}

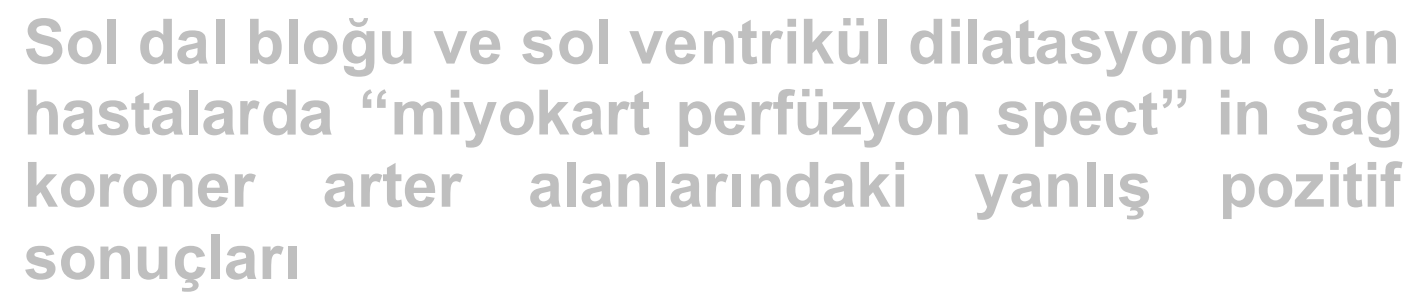

Serdar Savaş Gül ${ }^{1}$, Bülent Turgut ${ }^{2}$, Taner Erselcan ${ }^{2}$, *Zekiye Hasbek ${ }^{2}$

${ }^{1}$ Departments Of Nuclear Medicine, School Of Medicine, Gaziosmanpaşa University, Tokat, Turkey

${ }^{2}$ Departments Of Nuclear Medicine, School Of Medicine, Cumhuriyet University, Sivas, Turkey

Corresponding author: Dr. Zekiye Hasbek, Nükleer Tıp Anabilim Dalı, Cumhuriyet Üniversitesi Tıp Fakültesi, TR58140, Sivas, Türkiye.

E-mail: hasbekz@yahoo.com

Received/Accepted: February 26, 2015/August 29, 2015

Conflict of interest: There is not a conflict of interest.

\section{SUMMARY}

Objective: The aim of this study is to determine the diagnostic value of myocardial perfusion SPECT (MPSPECT) images in patients with complete left bundle branch block (LBBB) and left ventricular (LV) dilatation.

Method: 25 patients (16 female and 9 male whose mean age $68.2 \pm 7$ ) with complete LBBB and LVdilatation have been included in this study. 17 patients who have no typical scintigraphic perfusion abnormality have been evaluated as a control group. LV was divided into segments on the apical, mid and basal short-axis images, and visual perfusion scoring was performed on 1248 segments. Perfusion defects were classified as fixed or reversible. All demographic data and the ejection fraction $(\mathrm{EF})$ values of patients were expressed as average standard deviation. The relation between myocardial perfusion and coronary angiography (CAG) results were evaluated.

Results: In 25 patients who had coronary angiography, the positive diagnostic value of

MPSPECT for left anterior descending coronary artery (LAD) stenosis was $36 \%$, for left circumflex coronary artery (LCx) stenosis was $43 \%$, and for right coronary artery (RCA) stenosis was $16 \%$. Specificity values were $36 \%, 82 \%$ and $13 \%$ respectively.

Conclusion: Pharmacologic stress-rest MPSPECT imaging with dipyridamole in the same day increases diagnostic accuracy for detection of coronary artery disease (CAD) in patients with LBBB and LV dilatation. It should be considered that false positive ischemic results detected in RCA areas except for LAD areas in these patients also.

Keywords: Left bundle branch block, Left ventricular dilatation, T1-201, Tc-99m, MIBI, SPECT, dipyridamole

\section{ÖZET}

Amaç: Bu çalışmanın amacı komplet sol dal bloğu (LBBB) ve sol ventrikül (LV) dilatasyonu bulunan hastalarda miyokart perfüzyon SPECT (MPSPECT) görüntülemenin tanısal değerini belirlemektir.

Yöntem: LV dilatasyonu ve LBBB bulunan 25 hasta (16 kadın, 9 erkek, yaş ortalaması: 68,2 \pm 7 y1l) incelendi. Kontrol grubu olarak tipik sintigrafik perfüzyon anomalisi saptanmayan 17 hasta alınmıştır. Apikal, orta ve bazal kısa eksen görüntüleri üzerinde LV segmentlere ayrıldı ve 1248 segmentte vizüel perfüzyon skorlaması yapildı. Perfüzyon defektleri sabit veya reversibl olarak 
sinıflandırıldı. Hastaların tüm demografik verileri ile EF değerleri ortalama \pm standart sapma olarak ifade edildi. Perfüzyon değişiklikleri ile koroner anjiografi (KAG) sonuçları arasındaki ilişki değerlendirildi.

Bulgular: Koroner anjiografileri yapılan 25 hastada MPSPECT' in pozitif tanı değeri; sol ön inen koroner arter (LAD) stenozu için \%36, sol sirkümfleks arter (LCx) stenozu için \%43 ve sağ koroner arter (RCA) stenozu için \%16 idi. Spesifisite değerleri sırasıyla \%36, \%82 ve \%13 idi.

Sonuç: Bu hastalarda LAD alanı haricinde RCA alanında da yanlıș pozitif iskemi saptanabileceği göz önünde bulundurulmalıdır. Ayrıca LBBB ve LV dilatasyonu bulunan hastalarda koroner arter hastalığının (KAH) saptanmasında dipiridamol ile farmakolojik stres testinin, istirahat-stres Tc99m MIBI MPSPECT görüntüleme protokolü ile aynı gün uygulanması tanısal doğruluğu arttırmaktadır.

Anahtar sözcükler: Sol dal bloğu, sol ventrikül dilatasyonu, Tl-201, Tc-99m MiBİ, spect, dipiridamol

\section{INTRODUCTION}

Complete left bundle branch block (LBBB) is a defect of conduction system in heart for which the incidence increases with age. Male sex, advanced age (>65 years), hypertension (HT) and diabetes mellitus (DM) are major risk factors for $\mathrm{LBBB}^{1}$. In hearts with LBBB, the left ventricle (LV) walls could not contract simultaneously, leading to an increase in systolic and decrease in diastolic periods. Previous studies have showed a significant association between $\mathrm{LBBB}$ and coronary artery disease $(\mathrm{CAD})$ and hypertensive heart disease $^{2}$. Myocardial perfusion scintigraphy is a valid noninvasive method used for the evaluation of CAD, especially in cases with no diagnostic electrocardiographic changes such as LBBB. In these patients, vasodilator stress imaging is preferred to the exercise imaging for establishing $\mathrm{CAD}$ in LBBB pattern ${ }^{3}$. There is often high prevalence of perfusion abnormality especially in anteroseptal area in patients with LBBB even in the absence of CAD or severe left anterior descending coronary artery (LAD) occlusion. Thus, although having an advanced technology, noninvasive evaluation of LAD pathologies in patients with LBBB continues to be an important problem for nuclear cardiology ${ }^{4}$.

The aim of this study was to assess the diagnostic accuracy of MPSPECT imaging for right coronary artery areas in patients with LBBB and LV dilatation and also to define the causes of possible measures for false positive results.

\section{MATERIAL AND METHODS}

A total of 25 patients (16 female and 9 male) with a mean age of $68.2 \pm 7$ years (range, 55-84 years) and in whom electrocardiography shows LBBB and MPSPECT imaging shows LV dilatation were included in the study. Control group included 17 patients (10 female and 7 male) with a mean age of 50.9 \pm 9 years (range, 46-56 years) and in whom no scintigraphic perfusion anomaly was found after MPSPECT imaging. Treadmill and physical stress were applied to additional 9 TI-201-used patients (53\%) and to 8 Tc-99m MIBI-used patients (47\%). Coronary angiography (CAG) was performed only one patient in the control group and showed no significant stenosis in coronary arteries.

Pixel area and average counting were calculated by determining relevant area in heart and lung at anterior position on each MPSPECT projection imaging in both control and patient groups. LV areas were determined in stress and resting studies in the control group, with a mean value of $145.4 \pm 19$ pixel and $168.3 \pm 33$ pixel for stress and resting studies, respectively.

After the measurement performed by determining the relevant area in MPSPECT images showing LV dilatation, LBBB patients with a LV area higher than 250 pixels $\left(72.7 \mathrm{~cm}^{2}\right.$, in 64 x 64 matrix, 1.8 zoom parameter; 1 pixel is $0.053 \mathrm{~cm} 2$.) were included in the study ${ }^{5,6}$. LV areas of these patients in stress and resting studies were $328.4 \pm 78$ pixel and $344 \pm 89$ pixel for stress $(\mathrm{n}=23)$ and resting $(\mathrm{n}=25)$ studies, respectively.

All of the patients had a CAG which was performed by using standard percutaneous techniques within the last two weeks. A stenosis $\geq 50 \%$ in diameter was considered 
as significant coronary artery stenosis. MPSPECT results were compared with CAG results.

Echocardiography results were available for 21 of 25 patients (84\%), which showed a low global ejection fraction (EF) values $(34.4 \% \pm 7)$. None of the patients had experienced a myocardial infarction (MI) previously. Twelve patients $(48 \%)$ reported a previous diagnosis of dilated cardiomyopathy (DCMP) (Echocardiography results showed DCMP with an EF of $<45 \%$, enlargement in all cardiac cavities, wall thinning and congestive cardiac failure findings). Of these patients with DCMP, 5 (41.6\%) had ischemic DCMP and 7 (58.4\%) had non-ischemic DCMP.

Of the 25 patients, 15 (60\%) had a previous diagnosis of HT and 7 (28\%) had a previous diagnosis of HT and type 2 DM, while 3 patients $(12 \%)$ had no history of HT or DM.

Approximately $111 \mathrm{MBq}$ of sterile Thallium Chloride (TI-201, Mon-Talyum-201, Monrol Nuclear Products Industry Commerce Incorporated Company, Turkey) was quantified on a dose calibrator (AtomLab 100/Biodex Medical System, U.S.) and injected intravenously to all patients undergoing TI-201 MPSPECT. No preparation is needed for TI-201 which is a kind of cyclotron product.

Technetium-99m sestamibi (methoxy isobutyl isonitrile, MIBI), Unit Dose Cardio Spect ${ }^{\circledR}$ kit (Medi-Radiopharma Limited Company, Budapest, Hungary) was used in all patients undergoing Tc-99m MIBI MPSPECT by preparing a sterile, nearly 2 $3 \mathrm{ml}$ of $1110 \mathrm{MBq}$ non-pyretogen sodium pertechnetate Tc-99m solution. The vial ingredient was kept in boiling water for 10 minutes and left to get cold in room temperature. Radiochemical purity was assessed by paper chromatography and dosages which have only $\geq 90 \%$ binding percentage were administered to the patients within 6 hour after preparation. Pharmacological stress was induced by dipyridamol in 4 patients $(16 \%)$ in whom TI-201 was used and in 5 patients $(20 \%)$ in whom Tc$99 \mathrm{~m}$ MIBI was used. Treadmill and physical stress were applied to additional 11 TI201-used patients (44\%) and to $5 \mathrm{Tc}-99 \mathrm{~m}$
MIBI-used patients (20\%). Dipyridamole was applied intravenously in 4 minutes and with a dose rate of $0.142 \mathrm{mg} / \mathrm{kg} / \mathrm{min}$. Radiopharmasotic was injected intravenously in 7 minutes followed by SPECT imaging after 10 minutes for stress study and a resting imaging $3 \mathrm{~h}$ after the stress imaging. Tc-99m MIBI imaging was performed on the same day by using resting-stress SPECT protocol ${ }^{7}$.

SPECT data was stored in a dual head gamma camera: model; ECAM-5500 and manufactured year; 1996 (Toshiba Corporation, Japan). Topographic slices were created by filtered back-projection method and without using attenuation correction. Short axis, horizontal and vertical long axis images and polar maps were obtained from synchronous transaxial slices by processing the projection images. The same processes were used for stress and resting SPECT images.

Perfusion in "anterior, anterolateral, lateral, inferorolateral, inferior, inferoseptal, septum and anteroseptal" walls on LV apical, mid and basal short axis images and "apical, anterior and apical inferior" walls on mid vertical long axis images were observed visually by using " 26 segment- 5 grade perfusion scoring" (Picture 1). A perfusion score of 0 indicates that there is no perfusion defect, 1 indicates minimally reduced perfusion, 2 indicates moderately reduced perfusion, 3 indicates severely reduced perfusion and 4 indicates that there is no perfusion. In this scoring system, a score of 0-1 was considered as normal perfusion and 2-4 was considered as abnormal perfusion ${ }^{4,8,9}$. According to the arterial sites, apical anterior, apical inferior, septal, anteroseptal, anterior and anterolateral segments (segment 1, 2, 7, 8, 9, 10, $15,16,17,18,23,24,25$ and 26) represent LAD; lateral and inferolateral segments (segment 3, 4, 11, 12, 19 and 20) represent lateral circumflex artery (LCx); and inferior and inferoseptal segments (segment 5, 6, $13,14,21$ and 22) represent right coronary artery (RCA) ${ }^{10}$.

\section{Statistical analysis}

All demographical data of patients and EF values were expressed as mean \pm standard deviation. Perfusion scores obtained in 
every segment on LV during stress MPSPECT studies were compared with those obtained in resting MPSPECT studies and the differences between the images were analyzed. The rates of increase and decrease in segmental perfusion were calculated separately according to the arterial locations in every study. Significance of the difference in the heart-lung rates was analyzed between the patient and control groups. Patient data were evaluated by using "SPSS for Windows" statistical program and accuracy values were calculated.

\section{RESULTS}

The patients included into the study were categorized according to their vessel locations in which coronary stenosis were observed on CAG. There was a significant $(\geq 50 \%)$ coronary artery stenosis in any one of the three main coronary arteries in 9 patients $(36 \%)$. There were three vascular diseases in one patient and two vascular diseases in six patients and a single vascular disease in two patients. Clinical and angiographic data of all patients is shown in Table 1.

Myocardial perfusion scintigraphy (MPSPECT). LV dilatation was present on MPSPECT images of all patients. In the stress period SPECT images, abnormal perfusion (perfusion defect) was seen in $76 \%$ of the coronary arterial locations. With regard to the arterial location, of the perfusion defects, $43.4 \%$ (30.1\% reversible and $13.2 \%$ irreversible) was in LAD area, $13.2 \%(9.4 \%$ reversible and $3.7 \%$ irreversible) was in $\mathrm{LCx}$ area and $43.4 \%$ ( $18.8 \%$ reversible and $24.5 \%$ irreversible) was in RCA area.

There were 650 segments $(n=25)$ in the first imaging and 598 segments in the second imaging, with analyzing a total of 1248 segments (Only two patients had no second image).

Of the segments analyzed in the first imaging, 63\% showed a perfusion defect (segments with a perfusion score of 2-4) and $37 \%$ showed a normal perfusion (segments with a perfusion score of 0-1).

Reversibility was evaluated in a total of 1196 segments of 23 patients and perfusion defect on stress imaging was found in 226 of these segments (those with a perfusion score of 2-4), of which $41 \%$ showed a total reversibility in resting imaging (segments with a perfusion score of $2 \rightarrow 0,2 \rightarrow 1$ and $3 \rightarrow 1)$. Partial reversibility was seen in $37 \%$ of segments in which perfusion defect was found in stress period (segments with a perfusion score of $\rightarrow 2,4 \rightarrow 2$ and $4 \rightarrow 3$ ). On the other hand, reverse perfusion was found in $11 \%$ of the segments (segments with a perfusion score of $1 \rightarrow 2,2 \rightarrow 3$ and $3 \rightarrow 4$ ),

When segment scores were separately evaluated according to the arterial location, of a total of 644 segments $(n=23)$ in LAD area, 136 segments showed a perfusion defect in stress imaging (segments with a perfusion score of 2-4). Total reversibility, partial reversibility and reverse perfusion were found in $47 \%$ (segments with a perfusion score of $2 \rightarrow 0,2 \rightarrow 1$, and $3 \rightarrow 1$ ), $33.08 \%$ (segments with a perfusion score of $3 \rightarrow 2$ and $4 \rightarrow 3$ ) and $13 \%$ (segments with a perfusion score of $1 \rightarrow 2$ and $2 \rightarrow 3$ ) of these segments, respectively.

When 31 segments -in which perfusion change was determined on stress periodamong a total of 276 segments in LCx area was evaluated, total reversibility, partial reversibility and reverse perfusion was found in resting period in $22 \%, 12 \%$ and $12 \%$ of the segments, respectively.

When 59 segments -in which perfusion change was determined on stress periodamong a total of 276 segments in RCA area was evaluated, total reversibility, partial reversibility and reverse perfusion was found in resting period in 35\%, 59\% and $5 \%$ of the segments, respectively.

Visual evaluation of coronary artery area showed sensitivity, specificity and accuracy values as follows: when three arterial locations (LAD, LCx and RCA) were evaluated together, the sensitivity was $100 \%$, specificity was $31 \%$, negative predictive value (NPV) was $100 \%$, positive predictive value (PPV) was $28 \%$, false positive rate was $69 \%$, false negative rate was $0 \%$, diagnostic value was $45 \%$ and accuracy was $45 \%$.

There was a significant correlation between the heart/lung $(\mathrm{H} / \mathrm{L})$ rate obtained in the stress and resting periods in 23 patients 
$(\mathrm{p}<0.05)$. There was a significant difference between the stress and resting $\mathrm{H} / \mathrm{L}$ rates on TI-201 MPSPECT obtained from these patients and from those without DCMP. All other comparisons gave statistically insignificant results. The stress and resting $\mathrm{H} / \mathrm{L}$ rates on TI-201 MPSPECT in patients and controls were significantly different $(\mathrm{p}<0.05)($ Table 2$)$.

Projection, short axis and vertical long axis images of the Patient 24 who had significant coronary stenosis at CAG, LAD and LCx are shown on Picture 2. As seen on the picture, LV is dilated. Hypo-perfusions are seen as true positive (TP) in anteroseptal and inferolateral area and as false positive (FP) in inferior area. Apical inferior area in mid-vertical long axis is hypoperfused.

Projection, short axis and vertical long axis images of the Patient 25 who had no significant coronary stenosis at CAG are shown on Picture 3. Both ventricles are seen as to be dilated. Although hypoperfusion was determined as FP in anteroseptal and inferoseptal area, apical perfusion was preserved in mid-vertical long axis.

\section{DISCUSSION}

Noninvasive evaluation of LAD pathologies in patients with LBBB continues to be an important problem for cardiology. Among different protocols, intravenous dipyridamole or adenosine TI-201 imagining should be considered as reliable alternatives to the exercise protocol. Because, it increases the diagnostic accuracy of LAD stenosis associated with anterior, septal or apical ischemia in patients with LBBB. Some authors have suggested that because of reducing the incidence of FP septal perfusion abnormalities, Tc-99 MIBI SPECT may be more specific than TI-201 ${ }^{14}$. Relation between the wall thickness, wall thickening, wall motion and SPECT findings in determining MI has not been evaluated systemically in a clinical condition. Especially, even if leading to FP results, non-ischemic regional wall motion abnormalities and reduced wall thickness can lead to uncertainty in determination of infarct on SPECT images ${ }^{11}$. There are different results in the literature about the decrease in septal involvement in LBBB on TI-201 images, varying from $14 \%$ to $100 \%^{12,13}$.

Noninvasive diagnosis of $\mathrm{CAD}$ is very important for patients with the finding of LBBB on resting electrocardiogram. Diagnostic tests based on exercise make the diagnosis to be difficult because of changing electrophysiology. Moreover, myocardial perfusion imaging leads to FP results in nuclear stress laboratory. Several mechanisms have been suggested to explain the marked hypoperfusion found in LBBB patients on myocardial perfusion imaging are the actual decrease in septal perfusion due to decreased radionuclide uptake, the decreased septal thickening in resting period, and the inadequacy of the septum to be thickened in the stress period compared to the other segments. Thus, each unit volume number decreases relatively ${ }^{14}$.

It is known that FP reversible perfusion defects occur on MSPECT in anteroseptal wall and/or septum in $80 \%$ of the LBBB patients without $C A D^{15,16}$. We have evaluated diagnostic accuracy of MPSPECT imaging in our study which was carried out in patients with an electrocardiogram showing stable LBBB and LV dilatation. The rate of FP reversible perfusion defect was found as $56.5 \%$ for LAD area in our study.

Even though it is stated in previous studies that Tc-99m MIBI in MPSPECT study is more specific than TI- $201^{17}$, it is now considered that the type of radiopharmaceutical agent is less important in patients with LBBB. Stress technique used in these patients is more important ${ }^{18}$. In our study, sensitivity and specificity values obtained for Tc-99m MIBI and TI-201 in MPSPECT are similar, with being slightly higher for Tc-99m MIBI.

Dipyridamole is used in determining myocardial perfusion defects in patients with LBBB and is practical and clinically useful compared to the treadmill physical exercise. It has been found that FP rates of septal defects in determining CAD in patients with LBBB is significantly low in dipyridamole or adenosine imaging. Vasodilator stress imaging should be preferred to exercise imaging in these patients to determine the CAD in LBBB pattern ${ }^{3}$. It is 
stated in literature that FP for anteroseptal perfusion defects will decrease with using a pharmacologic agent such as dipyridamole instead of physical exercise. Similarly, in our study, a low rate of FP reversible defects was determined in patients on whom dipyridamole pharmacological stress and MPSPECT imaging were used.

Significantly increased $\mathrm{H} / \mathrm{L}$ rate will be the most important determinant of cardiac events in the future. As it is also present in TI-201 treadmill exercise images, increased lung involvement is the functional determinant of significant $\mathrm{CAD}^{19,20}$. The analysis of projection data of patients on whom MPSPECT imaging was performed gave similar results. Namely, statistically significant difference was found between $\mathrm{H} / \mathrm{L}$ rates obtained ruing stress and resting periods in patients in whom TI-201 radiopharmaceutical agent was used $(p<0.05)$.

It was suggested that in LAD area (anterior, anteroseptal and septal walls), CAG should be done only in patients with LBBB who have a reversible defect in comparison to to those with a stable defect. On the other hand, patients who have a stable or reversible defect in LCx and RCA area should be evaluated together with other clinical parameters (such as global LV EF and width of perfusion defect $)^{21}$. Similarly, FP reversible effects were observed in patients with LBBB who did not have CAD in our study. Interestingly, FP perfusion defects were seen in RCA area in addition to LAD area, which may be related to the presence of LV dilatation in patients with LBBB. MPSPECT FP results for the RCA areas is not specified in patients with $\mathrm{LBBB}$ and $\mathrm{LV}$ dilatation in the research literature. Analysis of enddiastolic SPECT images can help decreasing the FP results.

Absence of an apical defect is a specific finding for eliminating the LAD disease. Reversible defects in anteroseptal area and apex are reliable indicators for ischemia in LAD distribution (4). There are also some other studies supporting these findings ${ }^{22}$. Similarly, perfusion defect also was not found in apical segment in vertical long axis incision of patients with LBBB who has FP perfusion defects.

Because there are strict inclusion criteria (LBBB patients who have LV dilatation and whose $\mathrm{CAG}$ was present), there is a relatively low number of patients. Additionally, because of technical limitations, Gated MSPECT could not be performed, so perfusion images and LV wall motions were not evaluated together. Future clinical studies including more patients are needed to evaluate the role of MPSPECT in detail in determining the myocardial perfusion defects in LBBB patients with LV dilatation.

In conclusion; in our study, although sensitivity and specifity values in determining CAD in LBBB patients with LV dilatation were similar for TI-201 and MIBI applications, it has been found that diagnostic accuracy rate for Tc-99m MIBI is higher. With dipyridamole pharmacological stress and Tc-99m MIBI MPSPECT imaging, rate of perfusion defects in LAD and RCA is lower in comparison to other imaging protocols. We think that application of dipyridamole and pharmacological stress test in determining CAD with restingstress Tc-99 m MIBI MPSPECT imaging protocol on the same day would increase diagnostic accuracy in LBBB patients with LV dilatation. FP perfusion defect in RCA in addition to LAD can be seen in patients who is thought or suspected to have LBBB, LV dilatation and DCMP. Evaluation of the apical area from vertical long axis incision should not be missed. 
Table 1: Clinical data of all patients with LBBB, CAG and MPSPECT results.

\begin{tabular}{|c|c|c|c|c|c|c|c|c|c|c|c|c|c|}
\hline \multirow[b]{2}{*}{ Patient } & \multirow[b]{2}{*}{$\begin{array}{l}\text { Age } \\
\text { (years) }\end{array}$} & \multirow[b]{2}{*}{ Sex } & & & & \multicolumn{4}{|c|}{ Coronary Angiography } & \multicolumn{4}{|c|}{ MPSPECT } \\
\hline & & & & & & $\begin{array}{l}\text { ECHO } \\
(\%)\end{array}$ & $\begin{array}{l}\text { LAD } \\
(\%)\end{array}$ & $\begin{array}{l}\mathrm{LCx} \\
(\%)\end{array}$ & $\begin{array}{l}\text { RCA } \\
(\%)\end{array}$ & $\mathrm{RF}$ & $\begin{array}{l}\text { LAD } \\
\text { Area }\end{array}$ & $\begin{array}{l}\text { Lcx } \\
\text { Area }\end{array}$ & $\begin{array}{l}\text { RCA } \\
\text { Area }\end{array}$ \\
\hline 1 & 59 & M & & HT & $\mathrm{DM}$ & 44 & $\mathrm{~N}$ & $\mathrm{~N}$ & $\mathrm{~N}$ & $\begin{array}{l}\text { Tl- } \\
201\end{array}$ & FPr & FPr & FPr \\
\hline 2 & 64 & M & & & & 44 & 70 & 40 & 60 & MIBI & TPr & $\mathrm{TN}$ & $\mathrm{TPr}$ \\
\hline 3 & 60 & $\mathrm{~F}$ & DCMP & HT & & 34 & $\mathrm{~N}$ & $\mathrm{~N}$ & $\mathrm{~N}$ & MIBI & FP. & $\mathrm{TN}$ & FP. \\
\hline 4 & 55 & $\mathrm{~F}$ & & HT & DM & 26 & 20 & $\mathrm{~N}$ & $\mathrm{~N}$ & $\begin{array}{l}\text { MIBI } \\
\text { (dip) }\end{array}$ & $\mathrm{FPr}$ & $\mathrm{TN}$ & FPr \\
\hline 5 & 60 & $\mathrm{~F}$ & & HT & & 42 & 90 & 70 & 100 & $\begin{array}{l}\text { MIBI } \\
\text { (dip) }\end{array}$ & $\mathrm{TPr}$ & $\mathrm{TPr}$ & TPir \\
\hline 6 & 63 & $\mathrm{~F}$ & & HT & & 38 & 80 & $\mathrm{~N}$ & 70 & $\begin{array}{l}\text { MIBI } \\
\text { (dip) }\end{array}$ & $\mathrm{TPr}$ & FPr & TPir \\
\hline 7 & 55 & $\mathrm{~F}$ & DCMP & HT & DM & & $\mathrm{N}$ & $\mathrm{N}$ & $\mathrm{N}$ & $\begin{array}{l}\text { Tl- } \\
201 \\
\text { (dip) }\end{array}$ & TPir & $\mathrm{TN}$ & FPr \\
\hline 8 & 80 & $\mathrm{~F}$ & DCMP & HT & & 38 & 100 & $\mathrm{~N}$ & 70 & $\begin{array}{l}\text { Tl- } \\
201\end{array}$ & TPir & $\mathrm{TN}$ & TPir \\
\hline 9 & 69 & $\mathrm{~F}$ & DCMP & HT & DM & 24 & $\mathrm{~N}$ & $\mathrm{~N}$ & $\mathrm{~N}$ & $\begin{array}{l}\text { Tl- } \\
201\end{array}$ & FPr & $\mathrm{TN}$ & FPr \\
\hline 10 & 63 & $\mathrm{~F}$ & DCMP & HT & & 25 & $\mathrm{~N}$ & $\mathrm{~N}$ & $\mathrm{~N}$ & $\begin{array}{l}\text { Tl- } \\
201\end{array}$ & FPr & $\mathrm{TN}$ & FPr \\
\hline 11 & 62 & $\mathrm{~F}$ & & HT & & 35 & $\mathrm{~N}$ & $\mathrm{~N}$ & $\mathrm{~N}$ & $\begin{array}{l}\text { MIBI } \\
\text { (dip) }\end{array}$ & FPr & FPr & $\mathrm{FPr}$ \\
\hline 12 & 80 & $\mathrm{~F}$ & DCMP & HT & & 22 & 70 & $\mathrm{~N}$ & 60 & MIBI & TP. & $\mathrm{TN}$ & FP. \\
\hline 13 & 64 & M & DCMP & HT & & 36 & $\mathrm{~N}$ & $\mathrm{~N}$ & $\mathrm{~N}$ & $\begin{array}{l}\text { Tl- } \\
201 \\
\text { (dip) }\end{array}$ & FPr & $\mathrm{TN}$ & FPir \\
\hline 14 & 72 & M & & HT & & & $\mathrm{N}$ & $\mathrm{N}$ & $\mathrm{N}$ & $\begin{array}{l}\text { Tl- } \\
201 \\
\text { (dip) }\end{array}$ & FPir & $\mathrm{TN}$ & FPir \\
\hline 15 & 84 & F & DCMP & HT & & 33 & $\mathrm{~N}$ & $\mathrm{~N}$ & $\mathrm{~N}$ & MIBI & FPir & $\mathrm{TN}$ & FPir \\
\hline 16 & 69 & M & DCMP & & & 37 & 100 & $\mathrm{~N}$ & $\mathrm{~N}$ & $\begin{array}{l}\text { Tl- } \\
201\end{array}$ & TPir & FPir & FPir \\
\hline 17 & 76 & $\mathrm{~F}$ & & HT & DM & & $\mathrm{N}$ & $\mathrm{N}$ & $\mathrm{N}$ & $\begin{array}{l}\text { Tl- } \\
201 \\
\text { (dip) }\end{array}$ & FPr & $\mathrm{TN}$ & FPr \\
\hline 18 & 76 & M & & & & 26 & $\mathrm{~N}$ & $\mathrm{~N}$ & $\mathrm{~N}$ & $\begin{array}{l}\text { Tl- } \\
201\end{array}$ & $\mathrm{FPr}$ & $\mathrm{TN}$ & $\mathrm{FPr}$ \\
\hline 19 & 75 & $\mathrm{~F}$ & DCMP & HT & DM & 35 & 70 & $\mathrm{~N}$ & 30 & $\begin{array}{l}\text { MIBI } \\
\text { (dip) }\end{array}$ & $\mathrm{TPr}$ & $\mathrm{TN}$ & FPir \\
\hline 20 & 65 & M & DCMP & HT & & 25 & 100 & 100 & $\mathrm{~N}$ & $\begin{array}{l}\text { Tl- } \\
201\end{array}$ & TPir & TPir & FPir \\
\hline 21 & 68 & M & & HT & & 34 & 30 & 40 & $\mathrm{~N}$ & $\begin{array}{l}\text { Tl- } \\
201\end{array}$ & FPr & $\mathrm{TN}$ & FPir \\
\hline 22 & 66 & $\mathrm{~F}$ & DCMP & HT & DM & 33 & $\mathrm{~N}$ & $\mathrm{~N}$ & $\mathrm{~N}$ & $\begin{array}{l}\text { Tl- } \\
201\end{array}$ & FPr & $\mathrm{TN}$ & FPir \\
\hline 23 & 75 & $\mathrm{~F}$ & & HT & & 40 & $\mathrm{~N}$ & $\mathrm{~N}$ & $\mathrm{~N}$ & $\begin{array}{l}\text { Tl- } \\
201\end{array}$ & FPr & $\mathrm{TN}$ & FPir \\
\hline 24 & 71 & M & & HT & & & 80 & 90 & $\mathrm{~N}$ & $\begin{array}{l}\text { Tl- } \\
201\end{array}$ & $\mathrm{TPr}$ & TPr & FPr \\
\hline 25 & 75 & $\mathrm{~F}$ & & HT & & 52 & 30 & $\mathrm{~N}$ & 30 & MIBI & FPir & $\mathrm{TN}$ & FPir \\
\hline
\end{tabular}

Table 2: Correlation of stress and resting Heart/Lung activity rates.

\begin{tabular}{l|lll}
\hline & n & r & p \\
\hline Stress all group vs. Resting all group & 23 & 0.73 & 0.001 \\
Tl-201 Stress vs. Tl-201 Resting & 15 & 0.44 & 0.094 \\
Tl-201 DCMP Stress vs. Tl-201 DCMP Resting & 8 & 0.09 & 0.819 \\
Tl-201 Non-DCMP Stress vs. Tl-201 Non-DCMP & 7 & 0.92 & 0.003 \\
Resting & 8 & 0.95 & 0.001 \\
MIBI Stress vs. MIBI Resting & 10 & 0.10 & 0.783 \\
DCMP Stress vs. DCMP Resting & 13 & 0.95 & 0.001 \\
Non-DCMP Stress vs. Non-DCMP Resting & &
\end{tabular}

Tl-201: Thallium-201, MIBI: Technetium-99 m Sestamibi, DCMP: Dilated Cardiomyopathy 


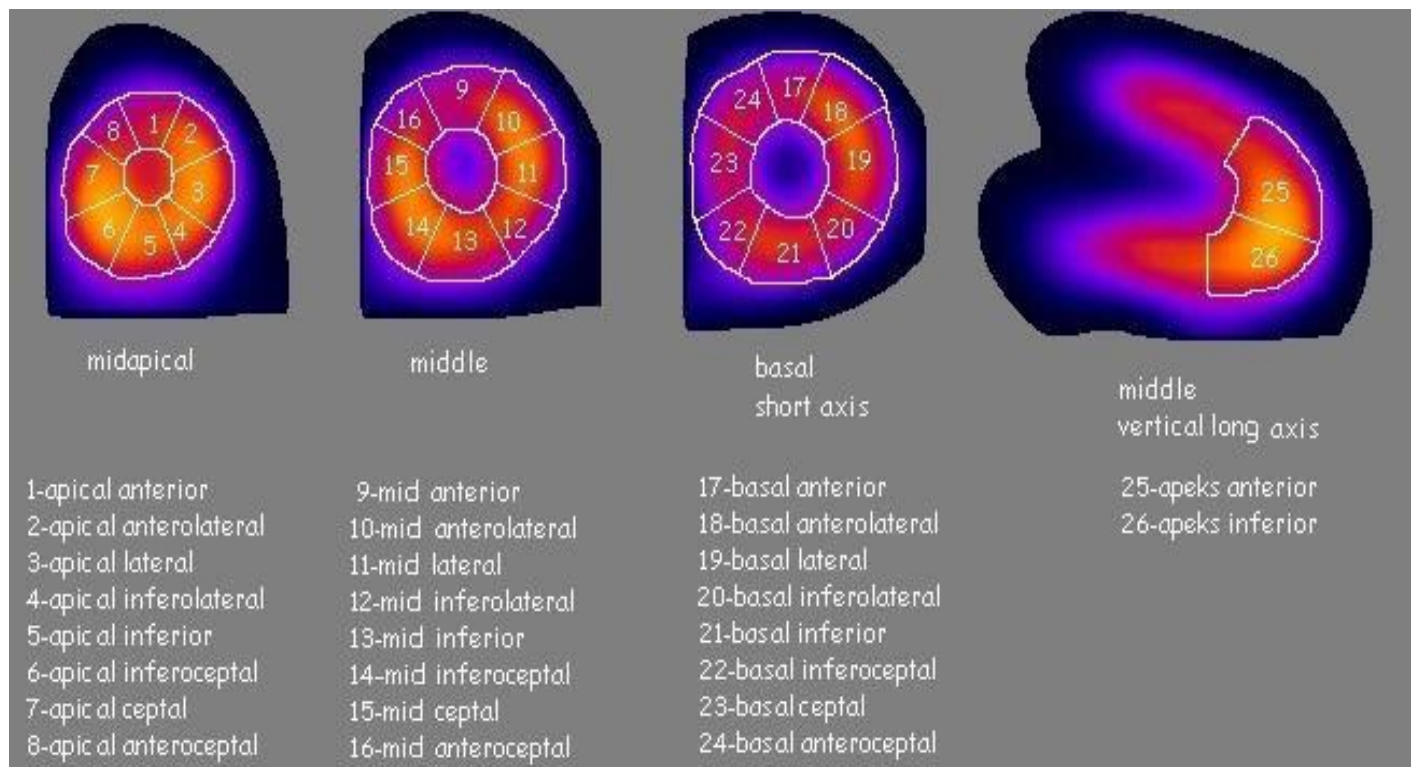

Figure1: Perfusion scoring on LV apical, mid and basal short axis and mid vertical long axis slices.

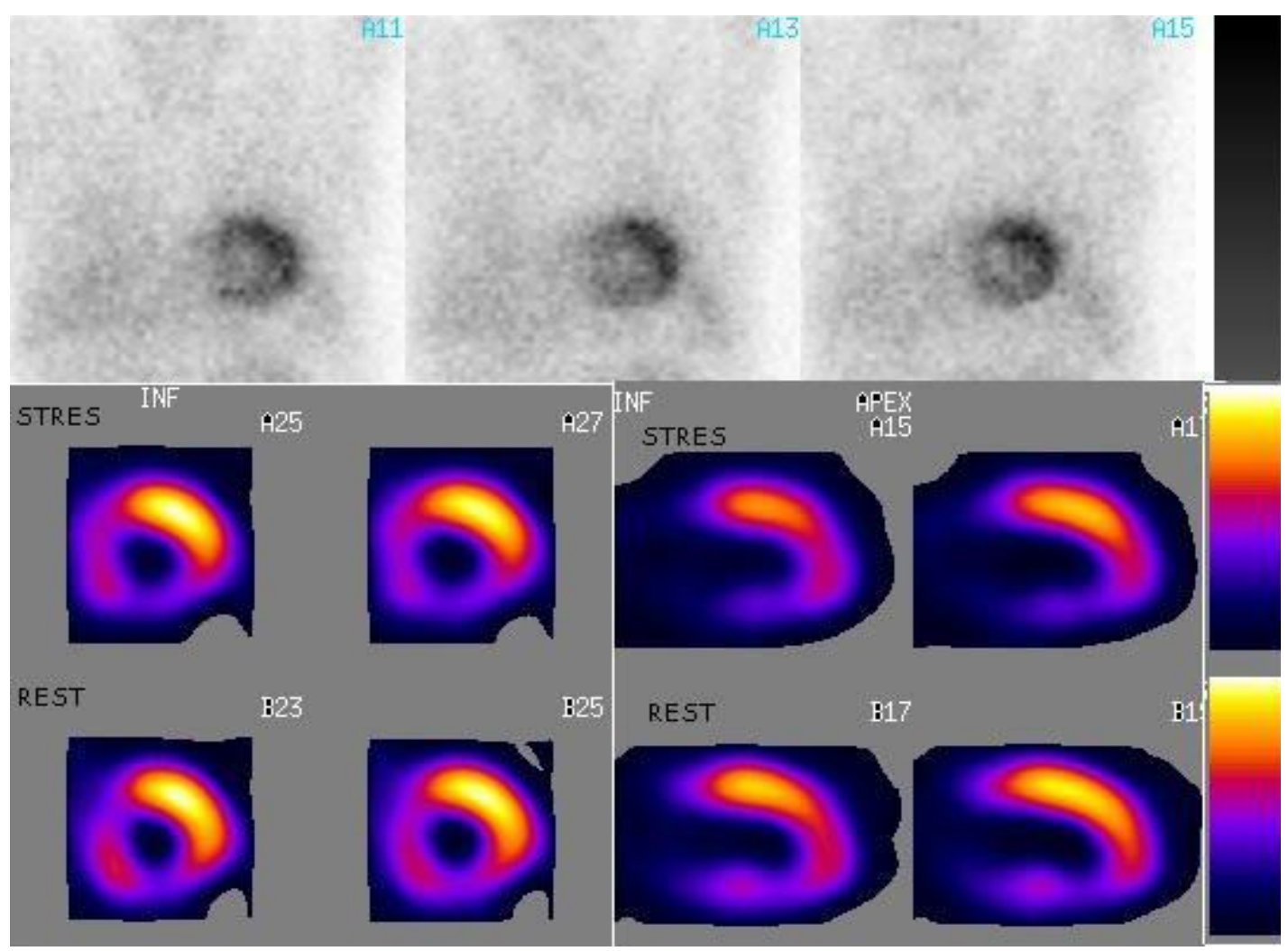

Figure 2: Projection, short axis and vertical long axis images of patient numbered 24. 


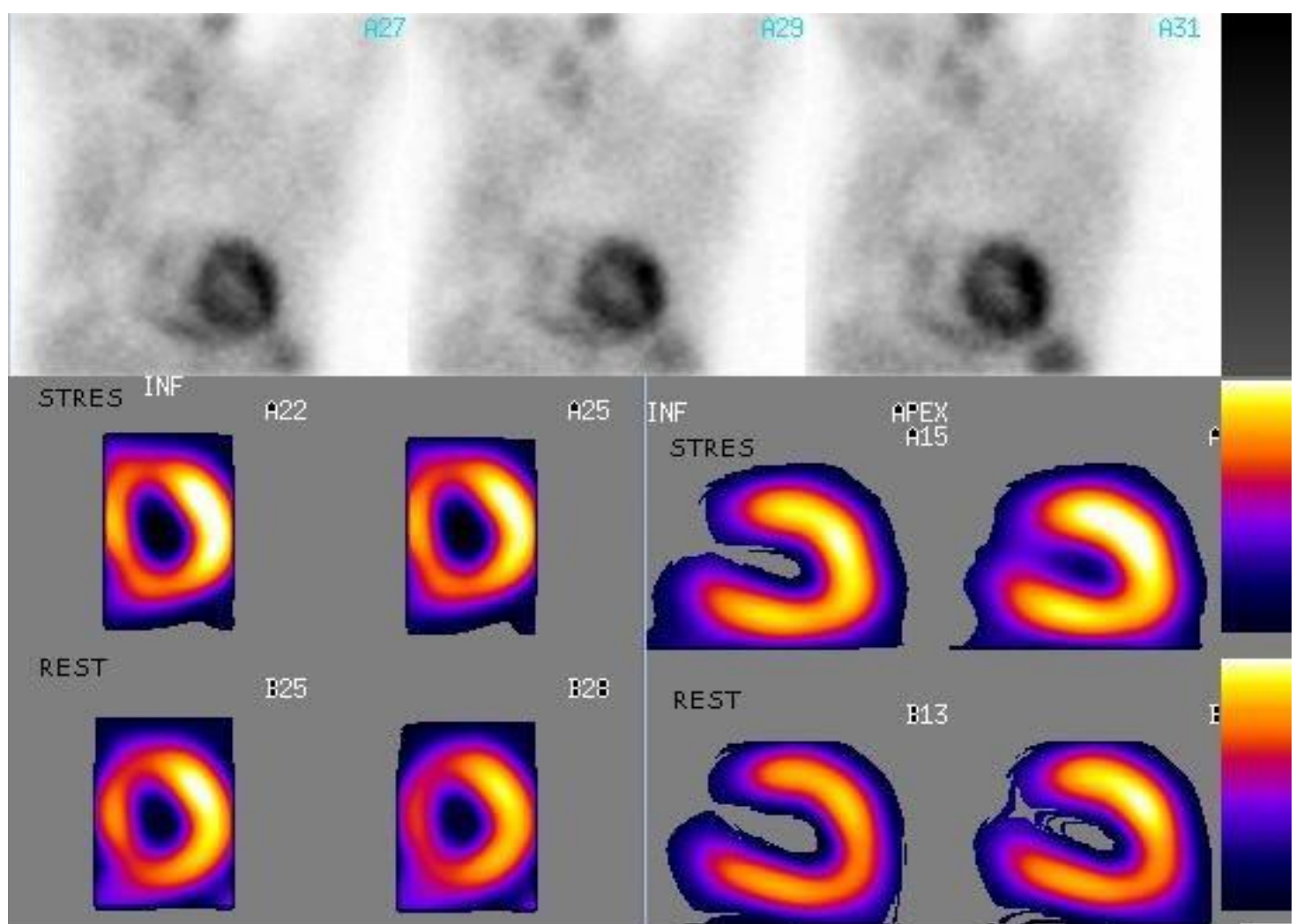

Figure 3: Projection, short axis and vertical long axis images of patient numbered 25.

\section{REFERENCES}

1. Jeong JH, Kim JH, Park YH, Han DC, Hwang KW, Lee DW, Oh JH, Song SG, Kim JS, Chun KJ, Hong TJ, Shin YW. Incidence of and risk faktors for bundle branch block in adults older than 40 years. Korean J Intern Med. 2004; 19: 171-8.

2. Lewis CM, Dagenais GR, Friesinger GC, Ross RS. Coronary arteriographic appearances in patients with left bundle branch block. Circulation 1970; 41: 299307.

3. Beller GA, Zaret BL. Contributions of nuclear cardiology to diagnosis and prognosis of patients with coronary artery disease. Circulation 2000; 101:1465-78.

4. Alexanderson E, Mannting F, Gomez-Martın D, Fermona S, Meaveb A. Technetium-99mSestamibi SPECT Myocardial Perfusion Imaging in Patients with Complete Left Bundle Branch. Archives of Medical Research 2004; 35: 150-6.
5. Brodov Y, Guetta V, Di Segni E, Chouraqui P.J. Clinical predictors of stress-induced transient left ventricular dilatation in patients with nonsignificant coronary disease. Clin Hypertens 2010; 12: 693-7.

6. Haji SA, Ulusoy RE, Patel DA, Srinivasan SR, Chen W, Delafontaine P, Berenson GS. Predictors of left ventricular dilatation in young adults (from the Bogalusa Heart Study). Am J Cardiol 2006; 98: 1234-7.

7. Ravizzini GC, Hanson MW, Shaw LK, Wong TZ, Hagge RJ, Pagnanelli RA, Jain D, Lima HS, Coleman RE, Bornes-Neto S. Efficiency Comparison between $99 \mathrm{mTc}$ tetrofosmin and 99mTc-sestamibi Myocardial Perfusion Studies. Nuclear Medicine Communications 2002; 23: 203-8.

8. Turgut B, Unlü M, Cengel A. Dobutamine Stress Tetrofosmin SPECT; Evaluation of Short RestStress Protocol and Head to Head Comparison with MIBI in Detection of Coronary Artery Disease. Annals of Nuclear Medicine 2005; 
19: $115-22$.

9. De Sutter J, Van de Wiele C, D'Asseler Y, De Bondt P, De Backer G, Rigo P, Dierckx R. Automatic quantification of defect size using normal templates: a comparative clinical study of three commercially available algorithms. Eur J Nucl Med. 2000; 27: 1827-34.

10. Hasbek Z, Turgut B, Erselcan T, Yalta K, Tandogan I, Ozer G, Ozdemir U, Turgut NH. Evaluation of myocardial viability with thallium-201 infusion MPSPECT after oral glucose application in patients with chronic coronary artery disease. Nuclear Medicine Communications. 2009; 30: 77988.

11. Mahrholdt H, Zhydkov A, Hager S, Meinhardt G, Vogelsberg H, Wagner A, Sechtem U. Left ventricular wall motion abnormalities as well as reduced wall thickness can cause false positive results of routine SPECT perfusion imaging for detection of myocardial infarction. European Heart Journal 2005; 26: 2127-35.

12. Knapp WH, Bentrup A, Schmidt $\mathrm{U}$, Ohlmeier H. Myocardial scintigraphy with thallium-201 and technetium-99m-hexakis methoxyisobutylisonitrile in left bundle branch block: a study in patients with and without coronary artery disease. Eur J Nucl Med 1993; 20 : 219-24.

13. Zammarchi A, Pitscheider W, Crepaz R, Oberhollenzer R, Erlicher A, Unterhuber E, Osele L, Braito E. Exercise 201-thallium myocardial scintigraphy in left bundle branch block $\mathrm{G}$ Ital Cardiol 1994; 24: 1103-13.

14. Higgins JP, Williams G, Nagel JS, Higgins JA. Left bundle-branch block artifact on single photon emission computed tomography with technetium Tc 99m (Tc-99m) agents: Mechanisms and a method to decrease false-positive interpretations. Am Heart J 2006; 152: 619-26.
15. Tandoğan I, Yetkin E, Ileri M, Ortapamuk H, Yanik A, Cehreli S, Duru E. Diagnosis of coronary artery disease with Tl-201 SPECT in patients with left bundle branch block: importance of alternative interpretation approaches for left anterior descending coronary lesions. Angiology. 2001; 52: 103-8.

16. Skowerski M, Mandecki T, Nowak S. Myocardial scintigraphy with technetium 99m MIBI in patients with left bundle branch block. Pol Arch Med Wewn. 1999; 102: 87783.

17. Ellmann A, Heerden PD, Heerden BB, Klopper JF. 99mTc-MIBI stress-rest myocardial perfusion scintigraphy in patients with complete left bundle branch block. Cardiovasc J S Afr 2001; 12: 2526.

18. Richter WS, Aurisch R, Munz DL. Septal myocardial perfusion in complete left bundle branch block: case report and review of the literature Nuklearmedizin 1998; 37:146-50.

19. Villanueva FS, Kaul S, Smith WH, Watson DD, Varma SK, Beller GA. Prevalence and correlates of increased lung/heart ratio of thallium-201 during dipyridamole stress imaging for suspected coronary artery disease. The American Journal of Cardiology 1990; 66:13248.

20. Goland S, Shimoni S, Livschitz S, Loutaty G, Azulay O, Levy R, Caspi A, Arditi A. Dipyridamoleinduced abnormal Tl-201 lung uptake in patients with normal myocardial perfusion: a marker of increased left ventricular filling pressures. J Nucl Cardiol 2004; 11: 305-11.

21. Feola M, Biggi A, Ribichi F, Camuzzini G, Uslenghi E. The Diagnosis of Coronary Artery Disease in Hypertensive Patients with Chest Pain and Complete Left Bundle Branch Block Utility of Adenosine Tc-99m Tetrofosmin SPECT Clin Nucl Med 2002; 27: 510-5. 
22. Möller J, Warwick J, Bouma H. Myocardial perfusion scintigraphy with Tc-99m MIBI in patients with left bundle branch block: Visual quantification of the anteroseptal perfusion imaging for the diagnosis of left anterior descending artery stenosis. Cardiovasc J S Afr 2005; 16: 95-101. 